\title{
Cuidado, Frágil: um processo criativo de dança e diferenças
}

\author{
Fabiana Andreia Mors \\ Universidade Federal de Santa Maria - UFSM, Santa Maria/RS, Brasil \\ E-mail: fabianna.mors@hotmail.com \\ Neila Cristina Baldi \\ Universidade Federal de Santa Maria - UFSM, Santa Maria/RS, Brasil \\ E-mail: neilabaldi@gmail.com
}

\section{Resumo}

Este artigo aborda maneiras outras de produzir dança com bailarinos com e sem deficiências para que atuem como protagonistas de suas próprias criações. Para isso, a pesquisa do processo de criação de Cuidado, frágil se utiliza de uma metodologia mista: auto-etnográfica e etnográfica, a partir de diários de bordo e registros fílmicos e de áudio. As cenas foram desenvolvidas a partir dos procedimentos - que tinham como eixo condutor buscar formas outras de produzir dança e as memórias dos artistas - e de discussões acerca deles. A obra propõe a discussão de como as pessoas se veem e são vistas, de como são rotuladas e segregadas. Ao final, a pesquisa conclui que as pessoas com deficiência podem ser protagonistas de suas obras e autônomas em suas criações, revendo modos de dançar e de criar danças. E que processos como estes são autoformativos para todos os envolvidos, sendo importante serem vivenciados por artistasdocentes, como formas de verificar invisibilidades e revê-las.
This article discusses other ways of producing dance with dancers with and without disabilities so that they act as protagonists of their own creations. For this, the research of the creation process of Cuidado, frágil (Care, fragile) uses a mixed methodology: auto-ethnographic and ethnographic, from logbooks and film and audio records. The scenes were developed from the procedures - which had as a guiding principle to seek other ways of producing dance and the artists' memories - and discussions about them. The work proposes the discussion of how people see and are seen, how they are labeled and segregated. In the end, the research concludes that people with disabilities can be protagonists of their works and autonomous in their creations, reviewing ways of dancing and creating dances. And that processes like these are self-formative for all involved, being important to be experienced by teacher artist, as ways to check invisibilities and review them.
Palavras-chave

Dança. Deficiência. Diferenças. Processo criativo. Autonomia.

\section{Keywords}

Dance. Disabilities. Differences. Creative process. Autonomy. 
Este artigo discute o processo de pesquisa da obra Cuidado, frágil, desenvolvida no Curso de Dança Licenciatura da Universidade Federal de Santa Maria, em 2019. A proposta era criar a dança com bailarinos(as) com e sem deficiência, de modo que ambos atuassem como sujeitos do processo. Esta questão se faz relevante por dois motivos: o modo como os(as) dançarinos(as) são vistos e o modo como atuam. Muitas vezes, as pessoas com deficiência são usadas como apoio, durante a dança, para pessoas sem deficiência, em que só evidenciam primeiramente a patologia, sem a compreensão de que o corpo na cena deve ser visto por inteiro, não apenas a deficiência. Outras vezes, em companhias de dança constituídas por pessoas com deficiência, estas pessoas são apenas reprodutoras de movimentos, ou seja, são bailarinos que não criam. Acrescenta-se ainda o fato de as criações, na maior parte das vezes, serem desenvolvidas por pessoas sem deficiência. Diante deste quadro, a pesquisa desenvolvida para a proposição do espetáculo Cuidado, frágil, propunha dar autonomia às pessoas com deficiência na construção de um processo criativo de dança contemporânea.

Para o desenvolvimento da pesquisa foi criado um grupo de trabalho constituído por pessoas com e sem deficiência, sendo boa parte delas ex-participantes do Projeto de Extensão Extremus - criado em 2001 pela professora Dra. Mara Rúbia Alves da Silva, que trabalha com pessoas com múltiplas deficiências: Anny Xavier de Arruda, César Leonardo Possani Barrozo - estes dois, cadeirantes -, Layana da Rosa Ferreira e Fabiana Andréia Mors, além da mestranda em Educação Djenifer Geske Nascimento, que nunca participou do projeto, mas é licenciada em Dança. As experimentações ocorreram de junho a outubro de 2019, com encontros duas vezes por semana - a depender dos membros do grupo - e duração de duas horas cada. O mês de novembro foi dedicado a ensaios e a obra foi apresentada em dezembro.

A abordagem metodológica da pesquisa foi de caráter misto: Autoetnográfico e Etnográfico, uma vez que de acordo com Meyer (2014), apro- ximar-se do campo da pesquisa em dança (e não somente sobre dança) a partir da corporeidade do artista-pesquisador tem sido um dos desafios mais instigantes na atualidade. A implicação dos próprios pesquisadores em práticas de dança impõe desafios epistemológicos e metodológicos, seja no âmbito universitário ou não. Para ela, as pesquisas auto e etnográfica são modos de resolver estes desafios.

Segundo Dantas (2016), a pesquisa Etnográfica, incluindo a Autoetnográfica, tem como estratégia de registro dos dados a disciplina diária da escrita, tanto da pesquisadora como dos participantes; a observação; o registro em vídeos e o feedback após a prática. Por isso, os instrumentos utilizados foram diários do processo criativo, de todos os participantes, além de filmagens e rodas de conversas após os encontros, para um feedback da prática.

Para a discussão da obra, será apresentado, inicialmente, o referencial teórico que baseou esta pesquisa - apoiado em pessoas com deficiência que trabalham com dança, como Carolina Teixeira (2010) e Kate Marsh (2019) - e posteriormente será feita a descrição dos principais procedimentos de criação usados na obra, bem como a discussão sobre os mesmos. Ao final, elencam-se as principais conclusões da pesquisa.

\section{Dança e diferenças}

De acordo com Teixeira (2010), entre 1980 e 1990, a cena da Dança Contemporânea começou a explorar a degradação da modernidade por meio de obras que discutiam situações de exclusão-opressão, relacionadas a questões de gênero, discriminação e exclusão social. Assim:

A dança na contemporaneidade vem permitindo cada vez mais a convivência de corpos diversos, enfraquecendo arraigadas imposições culturais aos atributos necessários a este corpo, do tipo perfeito ou imperfeito, belo ou grotesco, hábil ou deficiente. A multiplicidade e a diversidade caracterizam esta dança, com corpos híbridos nascidos da contaminação entre fontes culturais, técnicas corporais e gêneros artísti- 
cos distintos. É raro observar hoje um corpo que dance construído por meio de uma técnica específica e que responda a um só padrão estético. (NUNES, 2005, p. 46).

Ou seja, a Dança Contemporânea contribuiu para o surgimento da dança inclusiva/de pessoas com deficiência na cena, possibilitando que todas as pessoas pudessem dançar. No entanto, na história da dança, como afirma Marsh (2019), faltam registros sobre dançarinos com deficiência, o que dificulta a cronologia dos fatos:

[...] a falta de artistas com deficiência em posições de influência e poder de decisão na produção da dança "tradicional" significa que as vozes dos dançarinos com deficiência não são consideradas na nossa cultura de dança comum. A posição contemporânea dos dançarinos com deficiência é, em grande parte, consequência deles não estarem presentes no registro histórico da dança e em outras estruturas, como os programas de ensino de dança. (MARSH, 2019, p.133).

A autora acrescenta que:

As consequências dessa exclusão da história da dança são significativas para os artistas com deficiência. É difícil sonhar com o sucesso na dança quando se possui referências limitadas sobre os predecessores da prática atual. Nesse contexto, os dançarinos com deficiência são marginalizados; as representações históricas se limitam a objetos de anomalia e curiosidade [...] Isso deixa os dançarinos com deficiência em um "meio-termo", sem resgatarem um contexto histórico nem sonharem em ser líderes no contexto atual, o que tem consequências para os sonhos de liderança dos dançarinos com deficiência. A marginalização de figuras históricas no contexto da dança e deficiência, no qual indivíduos são representados como "anormais" e tenta-se "apagar" a deficiência, parece ter levado a uma situação na qual muitos dançarinos com deficiência rejeitam as ligações sendo realizadas com os dançarinos com deficiência que existem e existiram nos contextos culturais históricos. (Ibidem, 2019, p. 134).
Na Europa e nos Estados Unidos, no final dos anos 1980 e início dos anos 1990, surgem grupos com elencos formados por pessoas com e sem deficiências, como Candoco Company Dance ${ }^{1, \text { DV82 }}$ e AXIS Dance Company ${ }^{3}$, que inspiraram, no Brasil, o surgimento da Roda Viva Cia. de Dança, em Natal, em 1995. No entanto, diferente de outros países, cujos grupos começaram com formação artística definida a partir da experiência de seus fundadores, no Brasil grande parte surgiu de trabaIhos terapêuticos, de grupos de pesquisa em universidades ou Organizações Não-Governamentais (ONGs) como a Associação de Pais e Amigos do Excepcional (APAE). Ou seja, a dança era utilizada como ação criativa e processo de reabilitação. Atualmente, a dança realizada por pessoas com deficiência é chamada de Dança Inclusiva, e, segundo Teixeira:

Esse termo dialoga com as políticas de inclusão vigentes no país desde os anos de 1990 , sobretudo, as políticas da educação especial, que vêm sendo implantadas nas instituições de ensino brasileiras. O termo também se justifica pela ideia de que todos

1 Companhia de dança contemporânea criada por Celeste Dandeker e Adam Benjamin, em 1991, em Londres, focada na integração de bailarinos com e sem deficiência. No link https://www.youtube.com/watch?v=Utpg6A$5 \mathrm{fnWo \& t}=32 \mathrm{~s}$ é possível assistir um trecho do projeto "Comissão llimitada" para a Olimpíada Cultural (CANDOCO, 2012).

2 DV8 Physical Theatre é uma companhia de dança inglesa, criada em 1986. O nome DV8 (di-vi-eight) faz uma analogia ao termo em inglês "deviate" que significa desviar. A brincadeira com as palavras afirma a proposta do grupo em trabalhar com a diferença, o desvio, a singularidade. No link https://www.youtube.com/watch?v=NShJJr1ztkM é possível assistir um trecho da obra "The cost of living" (DV8 PHYSICAL THEATRE, 2012).

3 Axis Dance Company, criada em 1987, na Califórnia, oferece programas de educação e extensão de dança integrados sem paralelo. Do treinamento recreativo ao profissional, o AXIS cria acesso à educação em dança para pessoas de todas as idades, com e sem deficiência. No link https://www.youtube.com/watch?v=ua5Zd5CgCns é possivel assistir um trecho da obra "The beauty that was mine through the middle without stopping" (AXIS DANCE COMPANY, 2010). 
podem dançar ou ter acesso à prática da dança, compartilhando experiências e vivências de forma plural. (TEIXEIRA, 2010, p. 63).

No entanto, a própria autora questiona o termo: "Será que esse discurso não reproduz um novo modelo de exclusão?" (TEIXEIRA, 2010, p. 63). O uso do termo suscita alguns questionamentos, como o de que só os nomeados como Dança Inclusiva podem ter pessoas com deficiência e, ao mesmo tempo, não são vistos pela sociedade como os demais grupos ou companhias de dança. Além disso, outra questão que levantamos é o perfil dos grupos de artistas com deficiência: formados por pessoas com e sem deficiência, mas coordenadas por pessoa sem deficiência. A partir destas questões, o termo diferenças parece abranger mais, uma vez que não se refere apenas a pessoas com deficiência, mas também questões de raças, gênero etc., por isso a escolha do mesmo.

\section{Discussão sobre o processo criativo}

O trabalho criativo aqui descrito e discutido teve como eixo motor as lembranças, mas a partir do que Timm (2012, p. 167) diz: "E se não for mais do mesmo jeito que por tanto tempo guardei nas lembranças e fiz memória?". Ou seja, nossas imagens e rememorações, que aparecem no processo criativo, são transformadas ao longo de nossas vidas, ressignificadas no momento em que são ativadas e vividas de outra forma no ato criativo. Do mesmo modo que as lembranças, que surgem muitas vezes sem que racionalmente busquemos, os procedimentos de criação muitas vezes, aconteceram de forma não programada, desencadeados por questões levantadas e discutidas durante cada encontro.

Foi dessa forma que o primeiro procedimento se deu, a partir do problema de pesquisa: Como criar dança com bailarinos com e sem deficiência, de modo que ambos atuassem como sujeitos do processo. A partir dele, César sugeriu que iniciássemos a investigação na prática: experimentamos formas de nos movermos ao mesmo tempo em contato com o outro. Desta experimentação, surgiu a ideia dele ir para o chão, sair da cadeira de rodas, ação que nunca havia realizado, apenas havia saído da cadeira para o sofá, em casa, que são da mesma altura. Esse foi o nosso primeiro desafio: investigar alguns modos de fazer o César sair da cadeira de rodas até chegar ao chão. No primeiro momento, perguntamos para ele de que maneira seria mais confortável e segura, para podermos auxiliar. Ele sugeriu passar da cadeira de rodas para uma outra e depois deslizar ao chão. Para realizar essas transferências foi preciso duas pessoas, uma de cada lado. Ao chegar ao chão, foi sugerido que ele experimentasse o piso, prestando atenção na textura, na temperatura, no espaço. Ainda no chão, todos nos aproximamos da cadeira de rodas e a desmontamos juntos. Exploramos seus encaixes e desencaixes, sentindo suas formas, percebendo o tamanho, peso. Estas explorações iniciais, mais tarde, se transformaram em uma célula coreográfica.

Estávamos ali, experimentando formas outras de nos mover, a partir de um pensamento outro (WALSH, 2008) sobre o corpo e, consequentemente, pensamento outro sobre dança. Então, durante todo o processo, a busca pela maior autonomia dos bailarinos com deficiência foi pautada pelo entendimento de que é necessário transformar o que se diz, mas também como se faz (PALERMO, 2014). O que significa "repensar radicalmente não só nossas cenas, poéticas e estéticas, mas principalmente as pedagogias e metodologias de criação artística que as conformam." (LEAL et al., 2017, p. 26).

Em outro encontro, a partir do vídeo de Joy $L a b$ Research (JOINT FORCES DANCE COMPANY; NÚCLEO DANÇA ABERTA, 2013), do coreógrafo Alito Alessi, começamos a explorar deslocamentos individuais, sem indicação de níveis e apoio utilizado, com o intuito de perceber como nossos corpos se deslocam pelo espaço livremente, para então ver quais suas tendências. Geralmente nossas tendências nos levam para nossas técnicas de dança. No início de processos criativos, a partir de explorações e improvisações, é comum a busca por movimentos já dançados, uma vez que, para improvisar: 
[..] o corpo conta com um vocabulário e as experiências confirmam que quanto mais sólida for a formação deste corpo, mais apto estará a realizar as desarticulações a que se pretende [...] Para improvisar, um corpo precisa haver colecionado muitas experiências motoras. A sua capacidade de inovar parece depender totalmente de sua habilidade em haver adquirido muitos conhecimentos motores. (KATZ, 2006, p. 20-21).

Uma das participantes escreveu em seu diário de bordo a respeito do repertório de movimento, da identificação das tendências, assim como maneiras de buscar sair delas ${ }^{4}$ :

\begin{abstract}
Enquanto me movimentava comecei a pensar que estava 'enferrujada', pois fazia tempo que não parava para experimentar algo a não ser quando criava as sequências para dar aula. Depois comecei a pensar em movimentos de deslocamentos que eu gostava e porque gostava. Sinto que músicas mais lentas me fazem sempre percorrer os mesmos caminhos e músicas mais rápidas me ajudam mais, talvez porque eu goste mais de movimentos rápidos e com peso forte. Mas por que não poderia então explorar ações mais lentas, com peso leve? Tenho vícios em movimentos com fluxos interrompido, rápido e com peso forte e talvez goste mais porque são meus vícios, estou na zona de conforto.
\end{abstract}

Perceber suas tendências de movimentos e reconhecer quais são os primeiros movimentos acionados quando estamos investigando e explorando algo mais livre é o primeiro passo, para sair da 'zona de conforto'. Por outro lado, é evidente, também, que a diferença de experiências em dança se faz presente nas reflexões. No grupo havia três pessoas com experiência em dança fora do Projeto de Extensão - sendo uma licencianda e outra licenciada em Dança - todas sem deficiência. Por outro lado, as duas pessoas com deficiência tinham como grande experiência o Projeto de Extensão. É por isso que uma delas escreve:

4 Todas as transcrições dos diários de bordo serão colocadas com endentamento diferenciado.
No início não sabia o que fazer, como fazer, o que eu faria, se aquilo estava sendo avaliado, eu ficava naquela insegurança. [...]. Ficava naquela agonia. [...] Então eu fiquei naquela insegurança, porque no Projeto era mandado fazer o movimento, aqui não, a gente iria criar o movimento. [...] Pesquisar com o corpo, foi estranho porque eu nunca tive isso, depois que eu comecei a perceber aqui é um trabalho, mas um trabalho livre, é um trabalho onde vamos sentar em grupo e discutir tudo e não vamos passar por um supervisor e ele vai criar a coreografia e passar.

O que está em jogo aqui são conceitos de dança e formas de se dançar. Como dito no início deste artigo, a proposta desta pesquisa era desenvolver autonomia no processo de criação e a fala acima deixa claro que, até então, esta bailarina não havia passado por um processo assim. Wachowicz explica esta insegurança:

Por que sentimos estranhamento e desconforto ao observar uma criação artística diferente do padrão a que estamos acostumados? [...] $\mathrm{Na}$ verdade o que nos é familiar é uma informação que recebemos e repetimos várias vezes durante nossa vida [...] desconforto dá-se com informações não familiares que estão no ambiente, porque elas não têm fluência em nossa rede. (WACHOWICZ, 2008, p. 123).

A questão do conceito de dança e de formas diversas de se dançar se apresenta quando se tem pouco repertório corporal e estético ou quando este é restrito a uma estética ou técnica de dança. Soter (2012, s.n.) lembra que as escolas de dança são, muitas vezes, o único lugar de contato com práticas de dança - nesta pesquisa, duas pessoas tinham como grande referência apenas um projeto. Desta forma, o processo que vivemos poderia permitir a construção de novas concepções sobre dança contemporânea, e que todos revissem seus saberes e pensares sobre dança em geral.

A exploração das formas de deslocamento permitiu que dois dos integrantes - uma pessoa com e outra sem deficiência - investigassem maneiras de dançar juntos. Nesta pesquisa, foi possível perce- 
ber, por exemplo, a predominância do uso do lado do corpo com maior mobilidade. Desta percepção nasceu outro procedimento: o uso do plástico boIha - que poderia ser enrolado em uma parte do corpo, reduzindo nossa mobilidade, ou no deslocamento, no chão. Além disso, do ponto de vista estético e imagético, este material serve para embalar objetos frágeis, como forma de proteção, o que fazia sentido para o que estávamos propondo. Afinal, muitas vezes, as pessoas com deficiência são consideradas frágeis e, por isso, super protegidas, quase que colocadas em uma 'bolha social' que não thes ajuda a construir sua autonomia.

Por isso, uma grande faixa de plástico boIha, como se fosse um tapete, foi colocada no chão e, no primeiro contato, a exploração era livre de indicações. Ao longo da experimentação, foram sugeridas as seguintes indicações:

- Deslocar-se no tapete de plástico bolha tentando estourar o máximo de bolhas possíveis;

- Deslocar-se no tapete de plástico boIha tentando não estourar nenhuma bolha;

- Explorar outras formas de deslocamento sem ser caminhando no tapete de plástico bolha;

- Explorar o plástico bolha em grupo.

A sensação de estourar as bolhas com os pés, com meia e sem, era diferente, como também usar as mãos para estourar as bolhas. A parte mais desafiadora foi tentar não estourar as bolhas, parecia impossível, era preciso espalhar o peso igualmente na base que estava em contato com o plástico bolha. Desta exploração, nasceram duas células coreográficas: a cena inicial, em que a cadeira de rodas, vazia, atravessa o tapete de plástico boIha (puxada por um fio invisível) e a cena em que uma bailarina atravessa o palco, se enrolando no tapete de plástico bolha. Sobre este procedimento, uma das integrantes escreveu em seu diário:

Experimentamos individualmente movimentos usando plástico bolha. Primeiro me movimentei sozinha com o plástico bolha. Fiz movimentações que em sua maioria em rolamento, movimentos com as extremidades do corpo. Surgiram movimentos legais. Depois tive a ideia de utilizar uma cadeira na experimentação. Comecei tentando fazer os mesmos movimentos de antes com a cadeira. Depois comecei a colocar a cadeira em várias posições e envolver o plástico bolha em minha volta.

A imagem de Djenifer sentada na cadeira e envolvida num plástico bolha e um sonho com uma cena de uma cadeira de rodas envolta por uma bolha, rodeada por pessoas que a enchiam fez com que discutíssemos alguns significados dessa bolha: o isolamento que a pessoa com deficiência é colocada ou se coloca, a super proteção da família, o excesso de cuidado das pessoas não deficientes com estas e a limitação de espaços acessíveis a eles. Pensando na fragilidade e no isolamento, surgiu a imagem para o final: a cadeira de rodas com a bolha com um foco de luz, tendo presente ela desde o início da cena. Se o processo permitia que vivêssemos formas outras de dança, colocava-nos diante do entendimento do binômio exclusão-inclusão e das discussões sobre o quanto estas 'bolhas' surgem como formas de invisibilidade. Maldonado-Torres (2007, p. 257) diz que:

A invisibilidade e a desumanização são
as expressões primárias da colonialidade
do ser [...] A colonialidade do ser torna-se
concreta sob a forma de sujeitos limina-
res, que marcam, por assim dizer, o limite
do ser, ou seja, aquele ponto no qual o ser
destrói o sentido e a prova até o ponto da
desumanização. (MALDONADO-TORRES,
2007, p. 257 apud SANTOS, 2019, p. 42)

No final desse experimento, compartilhamos nossas percepções: muito se falou sobre o bloqueio em alguns momentos de estar dentro do plástico bolha, a sensação de agonia, sufocamento e de como sair dessa ideia de isolamento. Uma variação desse procedimento foi explorar com os participantes, em um único tapete de bolhas, investigando deslocamentos que poderiam ser feitos juntos.

Também experimentamos o plástico bolha simultaneamente no chão e cobrindo um espeIho móvel, de modo que a pessoa que estava no chão, sobre o plástico bolha, propusesse movi- 
mentos, que entrariam em diálogo com a pessoa em pé e, depois, o processo seria invertido. Um dos pontos que podemos pensar nessa experimentação é perceber as possibilidades de movimentos que as duplas criam e de que maneira podem ser feitos tanto em pé, deitado ou sentado.

Por sua vez, o procedimento de envolver o plástico bolha em uma parte de membro do corpo, ou seja, isolar o membro escolhido e movimentar apenas o restante do corpo, provocou vários questionamentos. Uma das participantes, uma bailarina sem deficiência, escreveu em seu diário:

Trabalhamos com a ideia de envolver o plástico bolha em uma parte do corpo e nos movimentarmos com as partes não imobilizadas. Primeiro, imobilizei as pernas, depois os braços. Foi muito difícil me mover sem poder me mexer com todas as partes. Ao mesmo tempo, essa experiência também me fez sair da zona de conforto, pude experimentar outras possibilidades. Pensando na ideia dessa experiência possibilitar uma vivência parecida com a que as pessoas com deficiência vivenciam em seu cotidiano eu acho que possa ser interessante no processo criativo, mas nunca vai ser a mesma experiência que eles.

Para o César foi sugerido que colocasse o plástico bolha no braço direito, que ele mais movimenta, o que proporcionou que dançasse utilizando outras partes do seu corpo.

Importante ressaltar que durante todo o processo de criação, alguns questionamentos surgiam do ponto de vista ético. Quando experimentamos isolar uma parte do corpo, ficamos pensando se fossemos levar para a cena, de qual maneira levaríamos. Como uma pessoa sem deficiência dançaria com uma parte isolada? Poderíamos deixar clara a parte isolada? Não estaríamos fazendo 'de conta' que era deficiente? Outra questão muito pertinente foi: em que parte do corpo colocaríamos o plástico bolha? Quando uma pessoa que não tem deficiência sentou em uma cadeira de rodas, dançando nela, também discutimos como resolveríamos essa situação. Percebemos que não haveria sentido, ela não sendo uma pessoa com deficiência ao dançar numa cadeira de rodas. Todas as nossas discussões éticas se refletiam em decisões estéticas, pois acreditamos que:

El arte como acto de reflexión permanente - y no solamente como el hecho de realizar objetos artísticos - debe contribuir a ensanchar los escenarios de discusión en torno de la exclusión social, la racializacion, la violencia genocida, la reafirmación de los estereotipos y el autoritarismo. De lo contrario - y quizá sea válido también - el arte se convierte en un ejercicio narcisista que nos lleva a producir objetos para la auto-satisfacción del campo del arte y todas las contigencias que lo acompañan. (ACHINTE, 2017, p. 23).

\section{Entre espelho e bonecas}

Como dito anteriormente, muitos dos procedimentos foram surgindo à medida da necessidade do grupo ou do processo criativo. Por exemplo, uma das participantes estava com muita dificuldade em criar e sugeriu que retomássemos uma coreografia elaborada em 2016 no Projeto de Extensão, em que uma pessoa se espelhava em outra. Ao contrário do que foi vivenciado naquela ocasião, a proposta era que agora ela criasse e a outra pessoa fosse seu espelho. Havia um bloqueio e resistência na criação, que vai ao encontro do que foi discutido anteriormente - as experiências em dança e em processos de criação. Neste sentido, propor um trabalho que é o oposto do que estão acostumados, gerou certa estranheza. Logo no início, sair do lugar cômodo provocou certos questionamentos e resistência, pois a proposta da pesquisa é que o grupo construísse junto uma obra, criada por ambos, sendo criadores, ou seja "[...] incentivar dançarinos(as) para sintonizar o que o corpo está expressando, considerar outras formas de expressão, e levá-los a pensar sobre o que eles estão fazendo, por que eles estão fazendo isso, e como eles estão fazendo isso". (MEAD, 2012, p. 2 apud BALDI, 2017, p. 149, grifo do autor).

Continuamos a experimentação do espelho, e investigamos alguns deslizamentos no chão. No entanto, havia sempre o questionamento sobre a 
'beleza' dos movimentos. A partir do questionamento sobre o que é belo e feio, fomos investigando experimentações que gostaríamos de fazer, ou tínhamos desejo de fazer. Até que, diante da resistência, surgiu a experimentação das bonecas, a partir do pensamento de manipulação: uma pessoa propunha, outra respondia. Deste experimento nasceu uma cena de marionetes, relacionando tanto na dança como na vida real em que a pessoa com deficiência se torna um objeto de manuseio das pessoas sem deficiência, ou são apenas um suporte de elevação, durante a dança, como citado anteriormente.

As bonecas - até aqui marionetes - começaram a surgir no processo em outros momentos. Um dia, uma das tarefas era gravar um vídeo com experimentações para compensar faltas em ensaios, de modo que a produção continuasse, mesmo quando não estivéssemos juntos. Um dos integrantes criou um videodança, que compartilhamos com o grupo e discutimos. Na conversa sobre a produção, ele explicou que queria usar bonecas, pois na sua infância, eram sua companhia e, apesar de não tê-las usado, havia a relação dele com as bonecas, em circunstâncias que viveu na sua infância, que a boneca estava presente e em outros momentos não, deixando claro o interesse em querer criar algo relacionando a bonecas. Um dia, após um ensaio, ele deu o seguinte depoimento:

No começo o uso das bonecas seria só uma parte do cenário, mas no decorrer de tudo eu comecei a lembrar da vez que conversamos sobre como as pessoas "normais" enxergavam nós cadeirantes, como coitadinhos, vamos dizer como objeto de manipulação. A partir daí comecei a perceber as bonecas nós podemos manipulá-las, então eu comecei a ver que as bonecas poderiam ser além de apenas cenário, poderia ser algo de manipulação para recordarmos o que as pessoas veem de nós e o que elas querem fazer com nós, ou seja, elas nos enxergam como coitadinhos e muitas vezes querem manipular a gente. Então as bonecas poderiam ser objetos de manipulação, eu vou manipular a boneca para que ela faça aquilo que eu queira. (BARROZO, 2019).
Seu depoimento desencadeou compartilhamento de memórias sobre bonecas e, a partir daí, passamos a construir uma cena com bonecas. Unimos, então, a ideia inicial das marionetes com as caixas de papelão que embalam bonecas e uma das integrantes estaria dentro dela (figura 1). Esta dançarina 'viveria' a história das nossas bonecas e, ao mesmo tempo, a cena poderia servir de reflexão sobre como a pessoa com deficiência é vista, como é colocada em 'caixas' diversas ao longo de suas vidas - inclusive de rótulos. E, como, mais uma vez, são marionetes, sem autonomia.

\section{Figura 1 - Cena da coreografia Maionetes.}

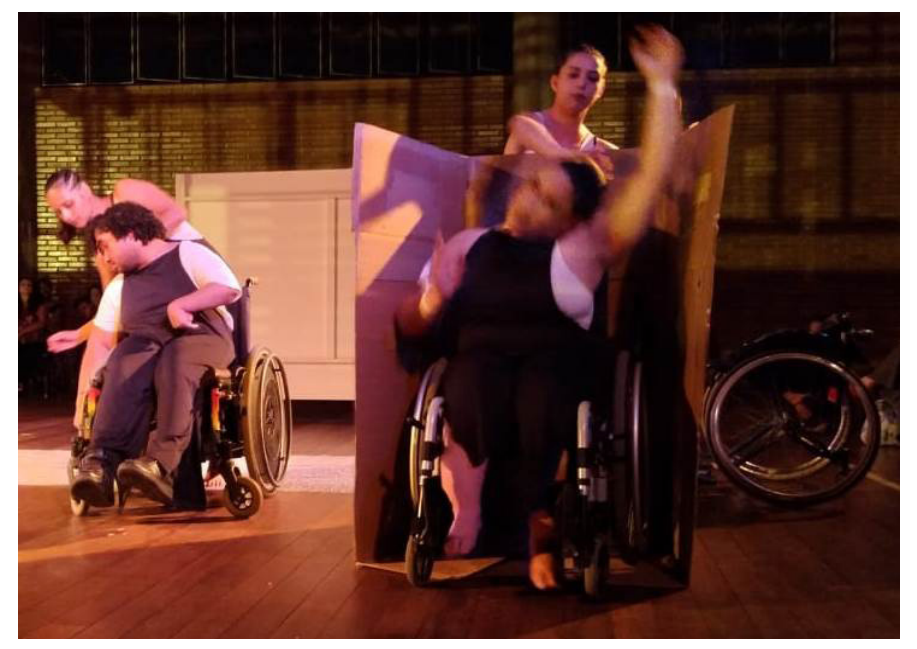

Fonte: Acervo pessoal.

Ao final, a cena se desencadeava para as duas pessoas com deficiência dançarem juntas. Até então, estávamos trabalhando em duos ou trios que mesclavam pessoas com e sem deficiência. Um dos integrantes, depois do ensaio, comentou: "No Extremus a gente nunca dançou juntos eu e a Anny, nunca passamos por isso. $\mathrm{O}$ mais perto que chegamos a dançar foi quando dançamos nós três, eu, você e Anny. Nunca dançou junto, nunca tentamos fazer uma coisa junto"5.

5 Transcrição da conversa gravada no dia 9 de novembro de 2019. 
Esta cena nos possibilita refletir sobre o que Teixeira diz a respeito dos dançarinos e dançarinas com deficiência:

Interessa-me refletir acerca da qualidade artística dos grupos e do papel do bailarino, artista que tem algum tipo de deficiência, enquanto figura autônoma no seu direito à construção do objeto artístico e não um mero coadjuvante, refém das hierarquias que se consolidaram na cena compreendida como inclusiva. (TEIXEIRA, 2010, p. 81).

Além disso, a cena não era única apenas para eles, mas também é incomum no mundo da dança, como relata Marsh:

Em relação à minha prática compartilhada específica com a dançarina Welly O'Brien (uma dançarina com uma perna), é raro ver dois artistas com deficiência em dueto juntos, especialmente duas artistas muIheres. Historicamente, a dança "integrada" tomou empréstimos de um modelo balético tradicional no qual a dançarina com deficiência interpreta um dueto com um artista sem deficiência, geralmente do sexo masculino (Jurg Koch e Welly O'Brien em Surfer Girl, de Doug Elkins, para a Candoco, 2001). (MARSH, 2019, p. 130).

\section{Considerações finais}

Ao final do processo, precisávamos escolher o nome da obra. Listamos diversos e, em grupo, chegamos a Cuidado, Frágil que, na nossa avaliação, se relaciona com o contexto de todas as cenas da obra, desde a caixa de papelão - embalada com fitas adesivas com este rótulo - até a proposição da discussão sobre como as pessoas com deficiência se veem e são vistas, de como são rotuladas e segregadas, além de usar como inspiração a história de vida dos bailarinos.

Neste sentido, esta pesquisa vai ao encontro de que pessoas com deficiência sejam protagonistas de suas próprias criações e que tenham autonomia na criação. $E$, na nossa avaliação, o processo de criação de Cuidado, frágil pode ter auxiliado estes bailarinos e bailarinas no aumen- to da autonomia, assim como possibilitado que vivenciassem e compreendessem outros modos de criação em dança e pensamento sobre dança.

Por meio das falas de compartilhamentos e discussões durante o processo, foi possível perceber em alguns momentos o reconhecimento das práticas de dança anteriormente realizadas, assim como notar que, ao longo do processo, eles verificaram que existe mais de um caminho para se fazer e produzir dança, sem que sejam da forma que estavam acostumados ou que tinham conhecimento. Isto não significa abandonar as outras formas de produzir dança, mas de reconhecer que existem maneiras diversas e que, a depender da obra, uma maneira outra será usada. Soter (2012) afirma que há uma multiplicidade de caminhos e que os métodos escolhidos dependem da obra, podendo variar conforme o artista ou a obra. Assim, "[...] se são tantos os caminhos possíveis para a criação em dança, a escolha de percorrer um ou outro dependerá das possibilidades de cada artista, de suas crenças, de suas posturas e das circunstancias da vida." (SOTER, 2012, s.n.).

Se a obra possibilitou aos integrantes um processo de autonomia não antes vivenciado, também permite, ao ser desenvolvida em uma licenciatura em Dança, discutir a importância do artistadocente conhecer o outro como pessoa, saber o contexto de onde vem, ter um olhar diferenciado e escuta do outro, saber como são seus dias, dar espaço para suas falas de compartilhamento do que estão vivendo - independente de estar lidando com pessoas com deficiência. Neste sentido, o processo foi um aprendizado para todos e todas, não só do ponto de vista artístico, mas também a respeito de inclusão. Durante a criação do espetáculo, os integrantes compartilharam as dificuldades de acesso tanto arquitetônico como a forma que eles são vistos em espaços de convívio na sociedade. Quando aprendemos, no nosso cotidiano, sobre a inclusão de pessoas com deficiência, podemos, também refletir sobre outras exclusões. Para um professor ou professora, isso é essencial.

Ficou evidente que, apesar de tantas falas sobre inclusão, as pessoas com deficiência ain- 
da são excluídas. Cuidado, frágil permite a quem usufrui da obra e a quem participa da mesma descobrir um pouco mais sobre inclusão e exclusão.

\section{Referências}

ACHINTE, Adolfo Albán. De la resistencia a la re-existencia: hacia una praxis decolonial del ser. In: ACHINTE, Adolfo Albán. Prácticas creativas de re-existencia: más allá del arte...el mundo de lo sensible.Ciudad Autonoma de Buenos Aires: Del Signo, 2017. p.13-27.

AXIS DANCE COMPANY. The beauty that was mine through the middle without stopping. Youtube. $15 \mathrm{dez}$. 2010. 4min30s. Disponível em: https://www.youtube. com/watch?v=ua5Zd5CgCns. Acesso em: 06 de jul. 2020.

BALDI, Neila Cristina. Por um balé somático: Cartas sobre o aprenderensinar balé clássico por meio das abordagens de Béziers e Laban/Bartenieff e do Construtivismo Pós-Piagetiano. 2017. 340 f. Tese (Doutorado em Artes Cênicas), Escola de Teatro, Universidade Federal da Bahia, Salvador, 2017.

BARROZO, César Leonardo Possani. [Explicação do videodança]. WhatsApp: [César]. 11 de ago. 2019. 8:58. 1 mensagem de áudio WhatsApp. 2019.

CANDOCO DANCE COMPANY. Southbank Centre. Youtube. 23 de ago. 2012. 3min18s. Disponível em: https://www.youtube.com/watch?v=Utpg6A5fnWo\&$\mathrm{t}=32 \mathrm{~s}$. Acesso em: 06 de jul. 2020.

DANTAS, Mônica Fagundes. Ancoradas no Corpo, Ancoradas na Experiência: Etnografia, Autoetnografia e Estudos em Dança. Urdimento (UDESC), v. 2, p. 168-183, 2016.
DV8 PHYSICAL THEATRE. The cost of living. Youtube. eGoSolidal. $14 \mathrm{de} \mathrm{fev.} \mathrm{2012.} \mathrm{4min54s.} \mathrm{Dispo-}$ nível em: https://www.youtube.com/watch?v=NShJJr1ztkM. Acesso em: 25 de jun. 2020.

JOINT FORCES DANCE COMPANY; NÚCLEO DANÇA ABERTA. Joy Lab Research. Youtube. 29 de maio 2013. $11 \mathrm{~min} 17 \mathrm{~s}$. Disponível em: https://www. youtube.com/watch?v=Md45iKiwgd8. Acesso em: 02 de jun. 2019.

KATZ, Helena. O coreógrafo como DJ. In: PEREIRA, Roberto; SOTER, Silvia. (Orgs.). Lições de dança 1. Rio de Janeiro: UniverCidade, 2006.

LEAL, Mara Lucia; ALCURE, Adriana Schneider; BACELAR, Camila Bastos; AZEVEDO, Maria Thereza. Pedagogias feministas e de(s)coloniais nas arte da vida. Ouvirouver, Uberlândia, v. 13, n.1, p. 24-39, jun. 2017.

MARSH, Kate. Ah... Você é tão bonitinha falando sobre deficiência... In: VENDRAMIN, Carla; BLADES, Hetty; MARSH, Kate; WHATLEY, Sarah. (Orgs.). Trocando, movendo, traduzindo: pensamentos sobre Dança e Deficiência. 1ed. Porto Alegre: UFRGS, 2019 , v. 1 , p. $127-146$.

MEYER, Sandra. Perspectivas auto-etnográficas em pesquisas com dança contemporânea. In: REUNIÃO BRASILEIRA DE ANTROPOLOGIA, 29, 2014, Natal, Anais...Natal: Universidade Federal do Rio Grande do Norte, 2014, p.1-10.

NUNES, Sandra Meyer. Fazer dança e fazer com dança: perspectivas estéticas para os corpos especiais que dançam. Ponte de Vista, Florianópolis, n. 6/7, p. 43-56, 2005. 
PALERMO, Zulma. Irrupcion de saberes "otros" en el espacio pedagógico: hacia una "democracia decolonial”. In: BORSANI, María Eugenia; QUINTE$\mathrm{RO}$, Pablo. (Comps.). Los desafíos decoloniales de nuestros días: pensar en colectivo. Neuquén: Educo Editorial de la Universidad Nacional del Comahue, 2014. p.123-150.

SANTOS, Boaventura de Sousa. Percursos para as epistemologias do Sul. In: SANTOS, Boaventura de Sousa. O fim do império cognitivo: as afirmações das epistemologias do Sul. Belo Horizonte: Autêntica, 2019. p. 41-63.

SOTER, Silvia. A criação em dança. In: INSTITUTO FESTIVAL DE DANÇA DE JOINVILLE (Org.). Criação, ética, pa..ra..rá pa..ra..rá Modos de criação, processos que desaguam em uma reflexão ética. 5ed. Joinville, 2012.

TEIXEIRA, Ana Carolina Bezerra. Deficiência em cena: desafios e resistências da experiência corporal para além das eficiências dançantes. 2010. $133 f$. Dissertação (Mestrado em Artes Cênicas). Universidade Federal da Bahia, Escola de Teatro/Escola de Dança, Salvador, 2010.

TIMM, Edgar Zanini. Histórias de vida: alguns aportes filosóficos-literários como contribuição à reflexão. In: ABRAHÃO, Maria Helena Menna Barreto; PASSEGGI, Maria Conceição. (Orgs.). Dimensões epistemológicas e metodológicas da pesquisa (auto) biográfica: Tomo I. 1ed. Natal; Porto Alegre; Salvador: EDUFRN; EDIPURS; EDUNEB, 2012, v. 1, p. 159-198.

WACHOWICZ, Fátima. Organismo dança contemporânea. In: XAVIER, Jussara; MEYER, Sandra; TORRES, Vera. Coleção Dança Cênica - Pesquisas em Dança. Joinville: Letradágua, 2008. p.119-132.
WALSH, Catherine. Interculturalidad, plurinacionalidad y decolonialidad: las insurgencias político-epistémicas de refundar el Estado. Tabula Rasa. Bogotá - Colombia, No.9: 131-152, julio-diciembre 2008.

Este é um artigo de acesso aberto distribuído sob os termos de uma Licença Creative Commons Atribuição 4.0 Internacional. Disponível em: http://creative commons.org/licenses/by/4.0.

This is an open-access article distributed under the terms of the Creative Commons Attribution License 4.0 International. Available at: http://creative commons.org/licenses/by/4.0.

Ce texte en libre accès est placé sous licence Creative Commons Attribution 4.0 International. Disponible sur : http://creativecommons.org/licenses/by/4.0. 